\title{
Colchicine (a high-priced alkaloid) accumulation and HPTLC quantification in different stages of in vitro developed tuber of Gloriosa superba L.
}

\author{
Dipika Rathod ${ }^{1 *}\left(\mathbb{D}\right.$, Jitendriya Panigrahi ${ }^{2}$ (D) and Illa Patel $\left.\right|^{3}$ (D)
}

\begin{abstract}
Background: Gloriosa superba L. belongs to Colchicaceae, which is an important medicinal plant containing highpriced alkaloid colchicines and other potent phytochemicals. Due to its extensive importance at the industrial level, this plant is overexploited. Moreover, indiscriminate harvesting for raw material leads to a decline in the population of this plant in the natural environment. Thus, the present study deals with the optimization of colchicine accumulation from the different intervals of in vitro and in vivo tubers of Gloriosa.

Result: To obtain in vitro tuberization, shoot tip explants were inoculated on Murashige and Skoog medium prepared with $3 \mathrm{mg} / \mathrm{l} \mathrm{BA}$ and $0.5 \mathrm{mg} / \mathrm{Kn}+1 \mathrm{mg} / \mathrm{l}$ 2, 4-D followed by $2 \mathrm{mg} / \mathrm{l} \mathrm{BA}+0.2 \mathrm{mg} / \mathrm{l} \mathrm{NAA}$. In the high-performance thin-layer chromatography study (HPTLC), the linearity range of colchicine was set at a concentration range of $100-1000 \mathrm{ng} / \mathrm{spot}$ with a regression value ( $\mathrm{r}$ ) of 0.99 . Its $R_{\mathrm{f}}$ value $(0.25)$ was recorded at $254 \mathrm{~nm}$. The colchicine amount in the in vivo tuber was $7.75 \pm 0.25 \%$ dry weight, while the nearby amount of $7.7 \pm 0.40 \%$ dry weight of colchicine was produced from 2 weeks in vitro old tuber. This value was followed by the 4th-week old tuber with $6.35 \pm 0.17 \%$ dry weight and then a gradual decrease in its accumulation.

Conclusion: The significant results for the accumulation of colchicine at different stages were observed. Hence, this strategy of colchicine production creates a new possibility for improved production of colchicine under in vitro conditions which will be helpful to various pharmaceutical industries without damaging the plants from the natural environment.
\end{abstract}

Keywords: Alkaloid, Colchicine, Gloriosa tubers, HPTLC

\section{Background}

Gloriosa superba L. is a seasonal climber, and it belongs to the family Colchicaceae. It is commonly known as vachhnag, kalahari, flame lily, and glory lily. Individual parts of this plant contain important phytochemicals including colchicine and are used for the treatment of various diseases like cancer, swelling,

\footnotetext{
*Correspondence: rathod.dipika7@gmail.com

${ }^{1}$ Department of Botany, H.V.H.P. Institute of Post Graduate Studies and Research, Kadi, Gujarat 382715, India

Full list of author information is available at the end of the article
}

leprosy, piles, gout, chronic ulcers. Moreover, this plant considers to have antipyretic, anti-anthelmintic, purgative, and anti-abortive properties and is used as an antidote in snake bites $[1,2]$. Seeds and tubers of this plant are a rich source of high-priced alkaloid colchicine. Owing to this, both parts are highly exploited for the extraction of colchicine. Further, the seed germination rate is found inefficient in this plant, and it is conventionally multiplied only by these two parts. So, the natural population of this plant is drastically declining. Furthermore, its unsustainable harvesting from the wild population for its colchicine content has 
been carried out by the pharmaceutical industries. In addition, it also faces a low seed set problem [3]. So, the mass multiplication of this valuable plant species is needed to meet the ever-increasing industrial demand. Consequently, in vitro propagation technology is now proven one of the potentially viable methods for the sustainable maintenance of many useful medicinal plant species [4]. At present, the biotechnological approaches especially plant cell, tissue, and organ culture have been proved as an effective source for the production and extraction of biologically potent secondary metabolites which now holds the attraction of many researchers. In recent times, more emphasis has been given to plant cell biotechnology which emerged as a possible alternative method for the production of active constituents, using in vitro cultured cells rather than destroying the whole plants from natural habitat for such extraction. However, there is little literature reported to date on the multiplication of this important tuberous plant $[5,6]$. Since the colchicine is mainly accumulated in the tuber, that's why the in vitro mass propagation/multiplication of the tuber part is essential [7]. Due to multiple uses of colchicine, in vitro technologies would be the best option to elevate the production of colchicine along with its improved properties. This technique provides a continuous, reproducible, and reliable source of the plant to meet the ever-increasing demand for pharmaceutical industries. It also fulfills disease-free plant materials on a large scale. In vitro propagated plant materials could also be useful to extract medicinally potent secondary metabolites without exploiting the plants from natural habitats [8-10]. Nowadays, high-performance thin-layer chromatography (HPTLC) is proven as a powerful tool for qualitative and quantitative analysis of vital bioactive compounds which are produced in various parts of plants. Consequently, it is considered as sophisticated among all other analytical techniques in terms of reliability, simplicity, speed, time, and cost per analysis $[11,12]$. Earlier, several researchers have used various chromatographic techniques like HPLC and HPTLC to determine colchicine from various plant parts of Gloriosa like seed, tuber, leaves, stem, flowers, pods, and seed pericarp [13-17] but a comparative account of in vitro and in vivo tuber was still lacking in Gloriosa. So, in the present investigation, an attempt was made for (1) in vitro tuber production and multiplication, (2) determination of colchicine in it and (3) optimization of the in vitro stage(s) for maximum accumulation of colchicines by using the HPTLC technique in both in vivo tuber and in vitro developed tuber at different developmental stages after method validation.

\section{Methods}

\section{Plant materials and chemicals}

The explants of Gloriosa superba L. were collected and selected for further studies. The chemicals used for the experiment were of analytical grade quality and were obtained from SD Fine, India, and Himedia, India. The Silica gel $60 \mathrm{~F}_{254}(20 \mathrm{~cm} \times 10 \mathrm{~cm})$ HPTLC plate used for the chromatographic studies was obtained from E. Merck (Darmstadt, Germany). The standard Colchicine was procured from Natural Remedies, Bangalore, India.

\section{In vitro tuberization}

For in vitro studies, terminal shoot tips were used as explants. The explants were washed with running tap water for 5-10 min. Then, all the selected explants were surface sterilized by dipping with $0.1 \%(\mathrm{w} / \mathrm{v})$ mercuric chloride for $0.5-1 \mathrm{~min}$ and at last rinsed thoroughly 2-3 times with sterile double distilled water. Sterilized explants were then inoculated into culture media under laminar airflow. The full-strength Murashige and Skoog (MS) [18] medium was prepared by supplementing various concentrations and combinations of plant growth regulators (PGRs) like $\mathrm{BA}$ ( $\mathrm{N}^{6}$-benzyl adenine) alone (1-3 $\mathrm{mg} / \mathrm{l})$, in combination with $\alpha$-naphthalene acetic acid (NAA). (NAA $0.2 \mathrm{mg} / \mathrm{l}$ ), combination of Kinetin +2,4-Dichloro phenoxy acetic acid (2,4-D) $(0.2+0.5$, $0.5+1$ and $1+1.5 \mathrm{mg} / \mathrm{l}$ ). The treatment without any PGRs was considered as a control. The $\mathrm{pH}$ of the medium was adjusted to 5.8 with $\mathrm{NaOH} / \mathrm{HCl}$ and dispensed into culture tubes and phytajars $(15-20 \mathrm{ml})$. The media was sterilized by autoclaving at $121{ }^{\circ} \mathrm{C}$ and $1.063 \mathrm{~kg} / \mathrm{cm}^{3}$ pressure for $20 \mathrm{~min}$. The cultures were maintained at $28 \pm 2{ }^{\circ} \mathrm{C}$ under $16: 8 \mathrm{~h} \mathrm{light/dark} \mathrm{photoperiod} \mathrm{under} \mathrm{cool}$ white fluorescent lamps at a photosynthetic photon flux density of $70 \mu \mathrm{mol} \mathrm{m}{ }^{-2} \mathrm{~s}^{-1}$. All the periodic data were collected for each parameter.

\section{Extraction procedure}

In vivo tubers of nearly two months were collected from the natural plant, whereas in vitro tubers have been developed through tissue cultures were harvested at different intervals of $2,4,6,8,10$, and 12 weeks of culture. All the samples were thoroughly washed with double distilled water and dried under shade at room temperature. Samples were powdered with a mechanical grinder and further extracted through a simple maceration method at room temperature. For extraction, $1 \mathrm{~g}$ powdered plant samples were mixed with $10 \mathrm{ml}$ of methanol and incubated for $24 \mathrm{~h}$ in the shaker at $200 \mathrm{rpm}$. After $24 \mathrm{~h}$, centrifugation was done and the supernatant was collected and filtered through Whatman filter paper No. 41. The obtained filtrate was concentrated and was used for further analysis $[19,20]$. A common stock solution of 
colchicine was prepared by dissolving it in methanol at the concentration of $1 \mathrm{mg} / 1 \mathrm{ml}$. The stock solution was then further diluted in methanol to obtain a solution containing the concentration of $100 \mathrm{ng} / \mu \mathrm{l}$ and was used as a working standard for the HPTLC study.

\section{Chromatographic conditions}

Chromatographic studies performed on a CAMAG HPTLC unit consist of Linomat-V automatic sample applicator, TLC scanner III, and integrated software WINCATS (CAMAG, Switzerland). The thin-layer chromatography was performed on a pre-coated silica gel HPTLC 60F254 $(20 \mathrm{~cm} \times 10 \mathrm{~cm})$ plate of $0.20 \mathrm{~mm}$ layer thickness, used as a stationary phase for the quantification of Colchicine. The plant samples and the standards were spotted on the TLC plate at 8-mm-wide bands with the help of the Linomat applicator $\mathrm{V}$ equipped with a $100 \mu \mathrm{l}$ syringe (Hamilton, Switzerland) under a continuous flow of nitrogen gas at a constant application rate of $150 \mathrm{nl} \mathrm{s}^{-1}$. Before placing the plate, Camag twin trough chamber $(20 \mathrm{~cm} \times 10 \mathrm{~cm})$ was saturated with $20 \mathrm{ml}$ mobile phase with chloroform/methanol: formic acid (20:1:0.2) for $20 \mathrm{~min}$, under room temperature $\left(28 \pm 2{ }^{\circ} \mathrm{C}\right)$ and $55 \pm 5 \%$ relative humidity. The spotted plate was then placed into a pre-saturated chamber and the chromatogram was run at $8 \mathrm{~cm}$ from the base. After that, the plate was dried with an air dryer and further quantitative evaluation was performed by scanning with TLC scanner III in the absorption-reflection mode at $254 \mathrm{~nm}$. The slit dimension was set at $6 \mathrm{~mm} \times 0.45 \mathrm{~mm}$, with a data resolution of $100 \mathrm{~nm} \mathrm{~s}^{-1}$ and scanning speed of $20 \mathrm{~mm} \mathrm{~s}^{-1}$.

\section{Method validation}

The present method was validated as per the ICH (International Council of Harmonization) guidelines [21]. For the linearity study, standard solutions at $100-1000 \mathrm{ng} /$ spot were analyzed. The calibration curve was generated by plotting the peak areas against the concentrations with the help of regression analysis. For the measurement of detection limit (LOD) and quantification limit (LOQ), the formula suggested by Alam et al. [22] was used. To measure the recovery study, the known samples were spiked with an extra $80,100,120 \%$ of the standard colchicine (standard addition method) and the mixtures obtained by this method were analyzed. The experiment was performed three times at each level.

\section{Precision, reproducibility, and specificity}

The system precision was estimated by using repeatability of the sample application, and peak areas were measured by using eight replicates of the same band (600 ng per spot of colchicine). The intraday and inter-day precision for colchicine was carried out by spotting eight samples at a concentration of $600 \mathrm{ng} / \mathrm{spot}$ that were analyzed on the same day and three different days, respectively. The precision was calculated in terms of relative standard deviation (\%RSD) of obtained peak area. The specificity of the present method was determined by comparing the obtained $R_{\mathrm{f}}$ values from TLC and the spectrum of the colchicine band from a plant sample with those of a standard.

\section{Quantitative determination of colchicine from in vivo and in vitro tubers}

Extracts of plant samples and standard solutions $(2,4,6,8,10 \mu \mathrm{l})$ were spotted on silica gel ${ }_{60}$ HPTLC plates of size $20 \mathrm{~cm} \times 10 \mathrm{~cm}$ and analyzed as mentioned above. The peak area of standard colchicine was determined from the calibration plot of peak area against the amount of colchicine (standard). The standard compound present in the different samples was determined by using a calibration plot, and data were recorded.

\section{Statistical analysis}

Completely randomized design (CRD) was used for performing tissue culture experiments. Each experiment was conducted with three replicates by using 10 samples. The recorded data were analyzed statistically using SPSS (version 20, SPSS Inc. Chicago, USA) software. The one-way analysis of variance (ANOVA) was used to determine the effect of treatment. Mean values of data were compared by Duncan multiple range test at $P \leq 0.05$.

\section{Results}

\section{Effect of PGRs on in vitro tuberization}

In the present study, initially, all cultures with treatments showed a white small bulbous/callus-like structure from the base of apical shoot tips within 2 weeks of culture, which eventually transformed into in vitro tubers after subculturing in the same medium for 12 weeks (Fig. 1). The controlled one did show a response, but it was meager at $20 \%$, while the number of in vitro tubers produced was only $2.26 \pm 1.1$. Among the various treatments, the highest percentage of growth frequency (90\%) with the maximum number of in vitro tubers $(37.7 \pm 0.5)$, as well as the significant growth of in vitro tubers, was observed when MS medium fortified with $3 \mathrm{mg} / \mathrm{l} \mathrm{BA}$ (Table 1) during all the stages. However, a lower concentration of 1 or $2 \mathrm{mg} / \mathrm{l} \mathrm{BA}$ hinders the overall growth of in vitro tubers. Among combined treatments, MS medium with Kinetin $(0.5 \mathrm{mg} / \mathrm{l})+2,4-\mathrm{D}(1.0 \mathrm{mg} / \mathrm{l})$ showed $70 \%$ of growth response with the $30.3 \pm 1.5$ numbers of in vitro tubers. However, a less or higher concentration than this combination considerably suppressed the growth of in vitro tubers. In contrast, the Kinetin $(0.2 \mathrm{mg} / \mathrm{l})$ in combination with 2 , 4-D $(0.5 \mathrm{mg} / \mathrm{l})$ showed $40 \%$ growth 


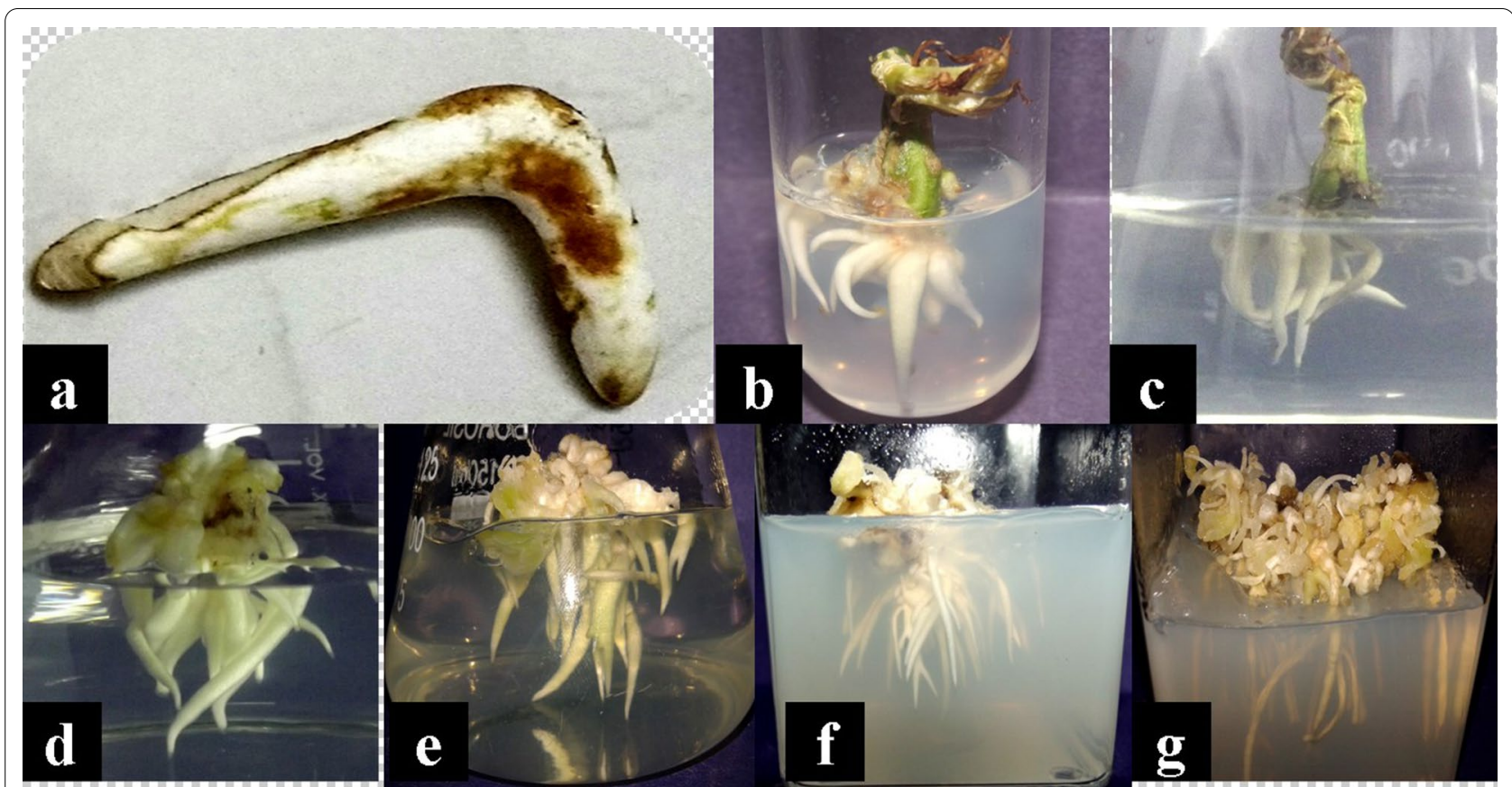

Fig. 1 a In vivo tuber, $\mathbf{b}-\mathbf{g}$ in vitro tuber culture in $\mathbf{b}-2, \mathbf{c}-4, \mathbf{d}-6, \mathbf{e}-8, \mathbf{f}-10$ and $\mathbf{g}-12$ weeks

Table 1 In vitro tuber formation in Gloriosa

\begin{tabular}{llll}
\hline Hormones types & $\begin{array}{l}\text { Concentration } \\
\text { (mg/l) }\end{array}$ & $\begin{array}{l}\text { \% Growth } \\
\text { response }\end{array}$ & $\begin{array}{l}\text { No. of microtubers/ } \\
\text { explants } \\
\text { (Mean } \pm \text { SE) }\end{array}$ \\
\hline Control & - & 2 & $2.26 \pm 1.1^{\mathrm{f}}$ \\
$\mathrm{BA}$ & 1 & - & - \\
& 2 & - & - \\
& 3 & 90 & $37.7 \pm 0.5^{\mathrm{a}}$ \\
$\mathrm{BA}+\mathrm{NAA}$ & $1+0.2$ & 50 & $26.3 \pm 1.5^{\mathrm{c}}$ \\
& $2+0.2$ & 60 & $31.3 \pm 1.1^{\mathrm{b}}$ \\
& $3+0.2$ & 20 & $25.0 \pm 1.7^{\mathrm{c}}$ \\
Kin.+2,4-D & $0.2+0.5$ & 40 & $21.6 \pm 0.5^{\mathrm{d}}$ \\
& $0.5+1.0$ & 70 & $30.3 \pm 1.5^{\mathrm{b}}$ \\
& $1+1.5$ & 30 & $14.3 \pm 1.1^{\mathrm{e}}$ \\
\hline
\end{tabular}

Data represent the mean \pm standard error of 10 replicates for each treatment. Means were compared using DMRT (Duncan's Multiple Range Test) $(P \leq 0.05)$ using one-way ANOVA. Mean values within the column with the same letter in superscript are not significantly different [34]

response with $21.6 \pm 0.5$ numbers of in vitro tubers but, when the concentration of these two combinations of Kinetin enhanced to $1 \mathrm{mg} / \mathrm{l}$ and 2, 4-D to $1.5 \mathrm{mg} / \mathrm{l}$, the growth response was declined (30\%) so as the number of in vitro tubers, i.e., $14.3 \pm 1.1$. However, in the case of BA + NAA, all three combinations provided a good response; but, still did not reach the highest percentage obtained from $3 \mathrm{mg} / \mathrm{l} \mathrm{BA}$ alone. Here, treatment using $2 \mathrm{mg} / \mathrm{l} \mathrm{BA}+0.2 \mathrm{mg} / \mathrm{l}$ NAA resulted in a significant
(60\%) response along with $31.3 \pm 1.1$ number of in vitro tubers. However, the combination of $3 \mathrm{mg} / \mathrm{l} \mathrm{BA}$ and 0.2 $\mathrm{mg} / \mathrm{l}$ NAA resulted in a significant decrease in growth response (20\%). Still decreasing number of in vitro tubers obtained in all the stages. Thus, tubers were collected from tubes with maximum growth at different stages and used for further analysis.

\section{HPTLC analysis \\ Method validation}

The mobile phase used in the present HPTLC study was selected by trying several combinations of different solvents. The preparatory TLC study revealed that chloroform, methanol, and formic acid (20:1:0.2 v/v) solvent system was found ideal that produced $R_{\mathrm{f}} 0.25$ for colchicine and gave sharp, clearly separated, and resolving bands. The chromatogram obtained was observed at $254 \mathrm{~nm}$ (Fig. 2). The spectrum obtained from the spectrum analysis was at $353 \mathrm{~nm}$. The observed peaks were relatively overlaying at $R_{\mathrm{f}} 0.25$. The peaks were matched precisely with each other that revealed the compounds are analogous to $R_{\mathrm{f}}$ of the markers and the respective in vivo and in vitro plant samples to be identical. The linear regression data for the calibration curve showed a good linear relationship with the linearity range of 100-1000 ng/spot. Moreover, a correlation coefficient $(r=0.99491)$ with a standard deviation (sdv) of $3.64 \%$ shows good linearity between concentration and area. 


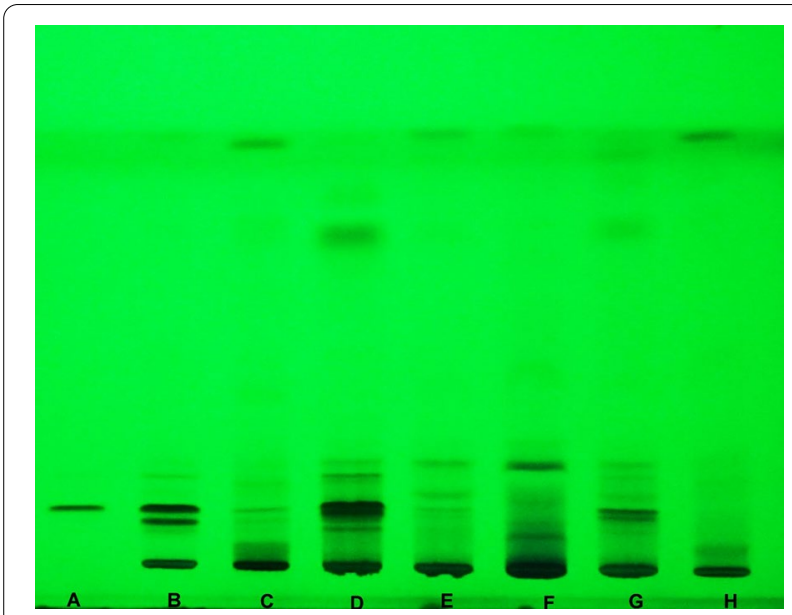

Fig. 2 TLC chromatograph of standard Colchicine with in vivo Tuber and in vitro tuber cultures at $\lambda=254 \mathrm{~nm}$ (A Standard Colchicine, B in vivo tuber, $\mathbf{C}-\mathbf{H}$ in vitro tubers with $\mathbf{C} 2$ weeks, D 4 weeks, $\mathbf{E}$ 6 weeks, $\mathbf{F} 8$ weeks, $\mathbf{G} 10$ weeks, $\mathbf{H} 12$ weeks)

The regression equation for this colchicine linearity was $Y=8519.241+0.810 * X$ (Fig. 3).

The observed value indicated good precision with RSD $5.86 \%$ (for intraday) and $5.78 \%$ (for inter-day) of the proposed method. The $148 \mathrm{ng} / \mathrm{spot}$ LOD and $447 \mathrm{ng} / \mathrm{spot}$ LOQ were also recorded which indicates that this proposed method was found sensitive for the quantification of colchicine. The recovery was analyzed by spiking the sample with 80,100 , and $120 \%$ of extra standard colchicine. The average recovery of colchicine was found to be $93.12 \%$. The specificity of the method was found by comparing the $R_{\mathrm{f}}$ value of the sample with the standard. The method proved to be specific for colchicine which resolved the compound at $R_{\mathrm{f}} 0.25$ in presence of other components. The peak purity of standard colchicine was confirmed by comparing spectra at three different levels, i.e., peak start, peak apex, and peak-end position of the band (Fig. 4). Simultaneously, Fig. 5 provides 3D view of the chromatograms with all tracks involved.

\section{Quantitative determination of colchicine content from in vivo and in vitro samples}

The validated method was applied to determine the amount of colchicine content in the in vivo tuber and in vitro tuber collected at different weeks. The quantified colchicine was expressed as percent dry weight (Table 2). However, maximum accumulation of colchicine content was observed in 2nd $(7.7 \pm 0.40 \%$ dry weight) and 4 th $(6.35 \pm 1.7 \%$ dry weight) week older in vitro tuber while, in vivo tuber $(7.75 \pm 0.25 \%$ dry weight) which is near to the 2 nd week older in vitro tubers. Nonetheless, the other weeks in vitro tubers increased in their length but were weak in producing the secondary metabolite-colchicine. The least amount of colchicine production was observed in the 12th week in vitro tuber (Table 2).

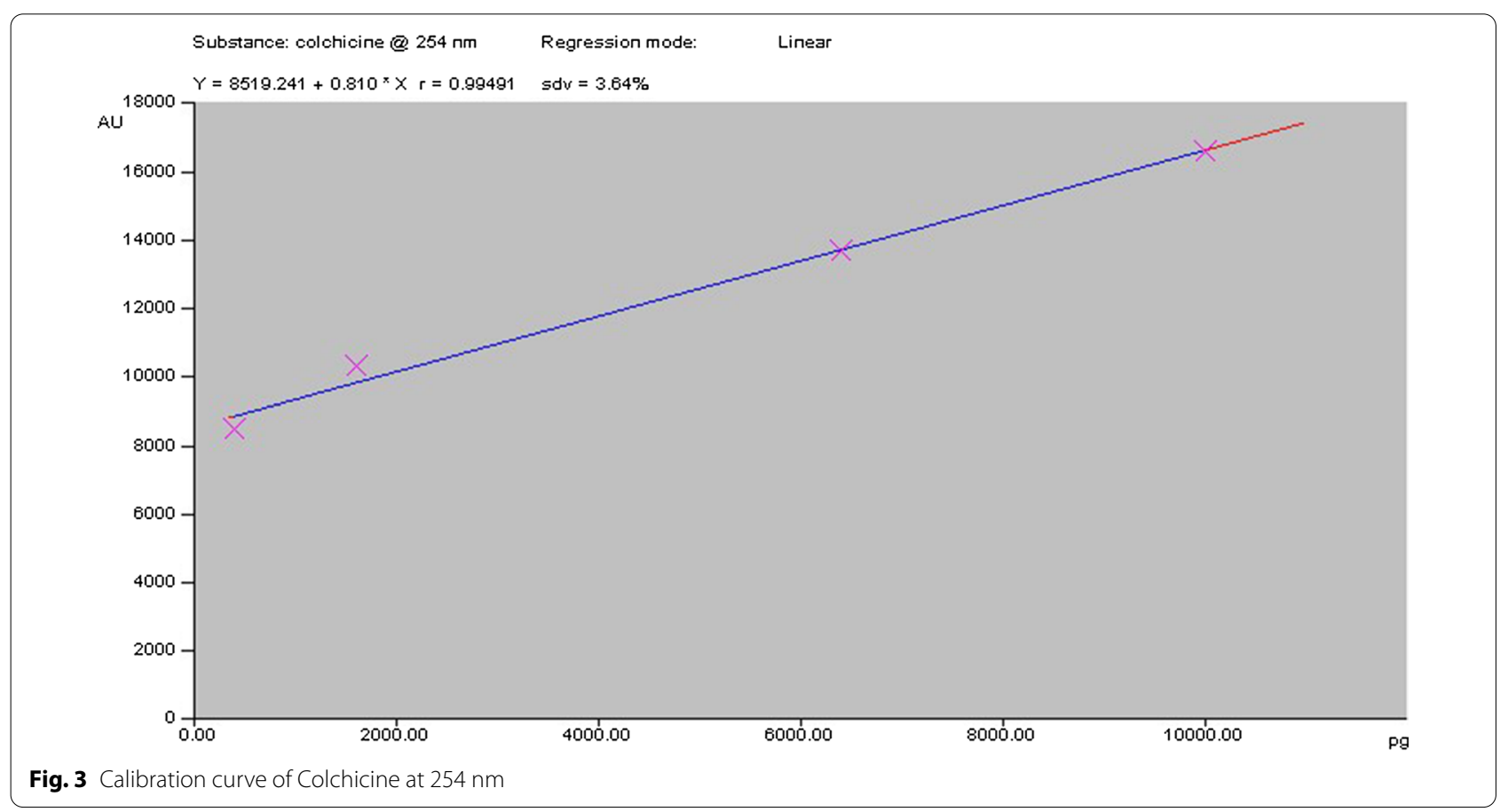



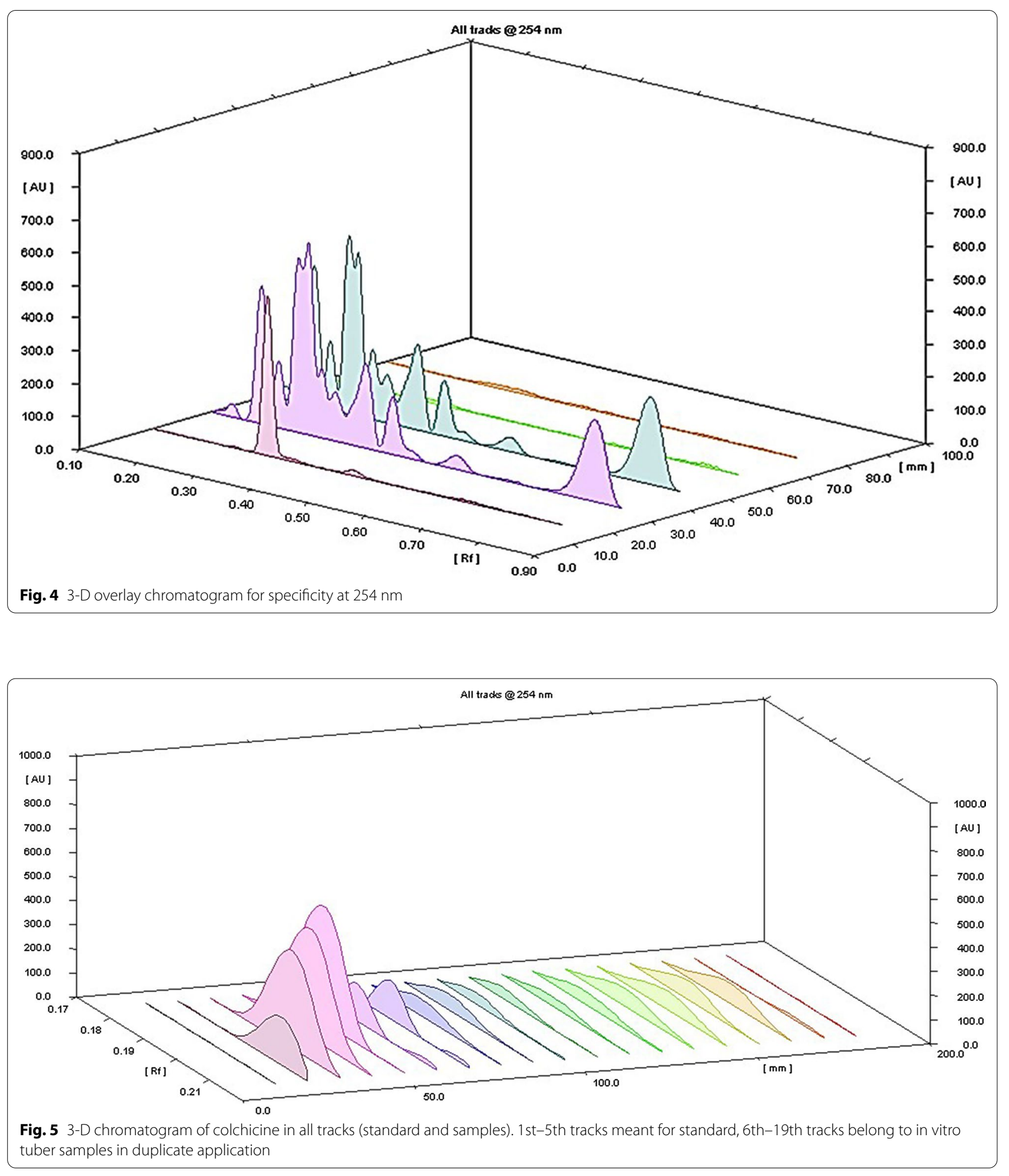

\section{Discussion}

The fast development of plant tissue culture and cell culture leads to the encouragement of the pharmaceutical industry to isolate more secondary metabolites on a large scale [23, 24]. Due to these biotechnological tools, secondary metabolite production can be achieved throughout the year. At times, the in vitro products produced a much higher amount within less time than in vivo as in 
Table 2 Quantification of colchicine content (mean \pm standard error bar, $n=3$ ) in in vitro and in vivo tubers of Gloriosa superba $\mathrm{L}$.

\begin{tabular}{lll}
\hline S. no. & Name of samples & $\begin{array}{l}\text { Amount of } \\
\text { colchicine } \\
\text { (\%) }\end{array}$ \\
\hline 1 & In vivo tuber & $7.75 \pm 0.25^{\mathrm{a}}$ \\
2 & In vitro tuber (2 weeks) & $7.7 \pm 0.40^{\mathrm{a}}$ \\
3 & In vitro tuber (4 weeks) & $6.35 \pm 0.17^{\mathrm{c}}$ \\
4 & In vitro tuber (6 weeks) & $5.71 \pm 0.46^{\mathrm{b}}$ \\
5 & In vitro tuber (8 weeks) & $3.27 \pm 0.45^{\mathrm{b}}$ \\
6 & In vitro tuber (10 weeks) & $3.03 \pm 0.34^{\mathrm{d}}$ \\
7 & In vitro tuber (12 weeks) & $1.78 \pm 0.22^{\mathrm{c}}$ \\
\hline
\end{tabular}

Column with same letters in superscript are not significant at $P<0.05$ based on one-way analysis of variance followed by Duncan's multiple range test [34]

our study where the 2nd-week in vitro tubers produced an almost equal amount of colchicine than in vivo tubers after its harvest. This may be the impact of the exogenous supply of hormonal combination that triggers the colchicine production. Though the other plant parts produce the colchicine, our findings based on in vitro tubers are the key source for colchicine. Thus, the current approach for optimization of colchicine production from in vitro stage(s) was reported to be less time-consuming and more economical.

The assenting effect of PGRs on the in vitro tubers production is essential as the endogenous content of the explants might not possess enough amount of growthregulating substance and therefore the culture media needed a proper quantity of hormonal doses which help the developing inoculated explants in proper proliferation. In this study, the synchronized effect of cytokinin (BA) and auxin (NAA) may produce the in vitro tubers albeit, not much that of cytokinin alone. This may be the endogenous content of the explant that favors the cytokinin more than that of auxin. Also, less than $3 \mathrm{mg} / \mathrm{l}$ concentration of BA did not meet the demand for the development of in vitro tubers. Likewise, 2, 4-D, and the kinetin did show the development of in vitro tubers still it is not up to the level of BA alone. This may be due to the inability of the amount of PGRs to convert the shoot tip to in vitro tubers. The positive influence of BA as a mostly used cytokinin source is well established in another medicinal plant [25]. Similar results were also obtained in G. superba [26]. The synergistic effect of cytokinins and auxins resulted in tuber formation in G. superba which is supported by previous reports $[5,27]$. In the initial phase of in vitro tubers production, the PGRs along with the micro- and macro-nutrients are directly involved in the growth and also some nutrients are also diverted for the secondary metabolite production. Moreover, less concentration of BA alone could be required for the in vitro tubers production. Therefore, the present outcomes of work are certainly an ideal protocol for the in vitro tuber production which would be useful for the more secondary metabolite production such as colchicine.

It was evident from this present study that colchicine could be produced in in vitro tubers of G. superba irrespective of weeks. Such aftermath undoubtedly emboldens the pharmaceutical industry to use both the samples to complement each other to fulfill the demand of $G$. superba based pharmaceutical companies for colchicine sources. One noteworthy observation is that the colchicine content in this study was superior to a previous report by Kumar et al. [28] who reported 0.08 and 0.10 percent colchicine in one and three months old tubers, respectively by HPLC. An earlier study, in vivo tuber, produced $0.057 \%$ dry weight as compared to $0.142 \%$ dry weight which was much less than the present study [28]. Significant variation in colchicine content was observed among the different weeks. Such significant production of colchicine endorsed to the controlled physical environment of growth containers, and also as the time progresses, the cell death may occur that leads to the decline in the production of secondary metabolite-colchicine. Colchicine is the very important bioactive compound of the alkaloid group. It can be produced through biotechnological approaches like a plant, cell, and tissue culture. Similar reports were available for the production of active bioactive compounds through plant tissue culture and their comparative study through HPTLC analysis in different in vitro tissues viz. Barbaloin [29], Gallic acid [30], Lignans [31], Stigmasterol [32], vasicinone [33].

\section{Conclusion}

In the present investigation, a rapid, reliable, and ideal protocol was developed for in vitro tuberization in Gloriosa. As the market value of colchicine was high enough, the sustainable production of in vitro tubers at different weeks makes it possible for the simultaneous production of colchicine. Therefore, the pharmaceutical industry gets benefitted from having more sources for extracting colchicine. A validated HPTLC method was developed for the determination of colchicine content from both in vivo and in vitro tubers. Hence, the inference of this present study can be used as an alternative source for colchicine in the standardization of many herbal formulations, as well as bring down the cost of it through the different stages of in vitro tuber production concurrent with the in vivo tubers.

\section{Abbreviations}

MS: Murashige and Skoog; PGRs: Plant Growth regulators; BA: ${ }^{6} \mathrm{~N}-$ Benzylaminopurine; 2,4-D: 2,4-Dichlorophenoxyacetic acid; NAA: Naphthalene Acetic 
Acid; HPTLC: High-Performance Thin-Layer Chromatography; LOD: Limit of Detection; LOQ: Limit of Quantification.

\section{Acknowledgements}

The authors are highly thankful to the University Grant Commission, New Delhi to provide the grant as RGNF, JRF for this study. We are also thankful to Head, Department of Life Sciences, HNGU, Patan and Principal, Pramukh Swami Science and H.D. Patel Arts College, Kadi, Gujarat, India for providing necessary facilities to carried out this study.

\section{Plant authentication}

The explants of Gloriosa superba L. were collected from the local field of Palanpur $\left(24^{\circ} 09^{\prime} 21^{\prime \prime} \mathrm{N} 72^{\circ} 24^{\prime} 27^{\prime \prime} \mathrm{E}\right)$, Gujarat, India in the month of September. The specimen was identified and authenticated by Dr. Illa C. Patel, Associate Prof, Department of Life Sciences, Hemchandracharya North Gujarat University, Patan.

\section{Authors' contributions}

$D R$, JP and IP conceptualized and designated the study. DR carried out the experiments. JP and DR analyzed the data. IP guided for the manuscript preparation. DR and JP prepared the manuscript. All authors have read and approved the manuscript.

\section{Funding}

The authors are thankful to the University Grant Commission, New Delhi to provide the grant as RGNF, JRF (F1-17.1/2012-13/RGNF-2012-13-SCGUJ-30906/(SA-II/Website) for this study.

\section{Availability of data and materials}

All analyzed data are included in this manuscript. Materials and data are available upon reasonable request.

\section{Declarations}

\section{Ethics approval and consent to participate}

Not applicable.

\section{Consent for publication}

Not applicable.

\section{Competing interests}

The authors declare that they have no competing interests.

\section{Author details}

'Department of Botany, H.V.H.P. Institute of Post Graduate Studies and Research, Kadi, Gujarat 382715, India. ${ }^{2}$ Department of Biotechnology, Shri A.N. Patel P.G. Institute of Science and Research, Anand, Gujarat 388001, India. ${ }^{3}$ Department of Life Sciences, Hemchandracharya North Gujarat University, Patan, Gujarat, India.

Received: 1 April 2021 Accepted: 22 August 2021

Published online: 28 August 2021

\section{References}

1. Samy RP, Thwin MM, Gopalkrishnakone P, Ignacimurthy S (2008) Ethanobotanical survey of folk plants for the treatment of snakebites in southern part of Tamilnadu. Indian J Ethanopharmacol 115:302-312

2. Veeraiah S, Reddy JK (2012) Current strategic approaches in ethnomedicinal plants of Tinospora cordifolia and Gloriosa superba - a review. Int J Pharm Bio Sci 3:321-326

3. Jana S, Shekhawat GS (2011) Critical review on medicinally potent plant species: Gloriosa superba. Fitoterapia 82(3):293-301. https://doi.org/10. 1016/j.fitote.2010.11.008

4. Sivakumar G, Krishnamurthy KV, Hahn EJ, Paek KY (2004) Enhanced in vitro production of colchicine in Gloriosa superba L. - an emerging industrial medicinal crop in South India. J Hortic Sci Biotechnol 79:602-605. https:// doi.org/10.1080/14620316.2004.11511813
5. Custers JBM, Bergervoet JHW (1994) Micropropagation of Gloriosa: towards a practical protocol. Sci Hortic 57:323-334. https://doi.org/10. 1016/0304-4238(94)90115-5

6. Sivakumar G, Krishnamurthi KV, Rajendran TD (2003) In vitro corm production in Gloriosa superba L., an Ayurvedic medicinal plant. J Hortic Sci Biotechnol 78:450-453. https://doi.org/10.1080/14620316.2003.11511648

7. Ade R, Rai M (2010) Colchicine, current advances and future prospects. Nusant Biosci 2:90-96. https://doi.org/10.13057/nusbiosci/n020207

8. Dicosmo F, Misawa M (1995) Plant cell and tissue culture: alternatives for metabolite Production. Pergamon Biotechnol Adv 13:425-453. https:// doi.org/10.1016/0734-9750(95)02005-N

9. Mulabagal V, Tsay H (2004) Plant cell cultures: an alternative and efficient source for the production of biologically important secondary metabolites. Int J Appl Sci Eng 2:29-48. https://doi.org/10.1016/S0168-1656(98) 00195-3

10. Vanisree M, Lee C, Lo S, Nalawade SM, Lin CY, Tsay H (2004) Studies on the production of some important secondary metabolites from medicinal plants by plant tissue cultures. Bot Bull Acad Sin 45:1-22

11. Patel R, Patel M, Dubey N, Patel B (2012) HPTLC method development and validation: strategy to minimize methodological failures. J Food Drug Anal 20:794-804. https://doi.org/10.6227/jfda.2012200408

12. Agatonovic-Kustrin S, Morton DW, Mizaton HH, Zakaria H (2018) The relationship between major polyphenolic acids and stigmasterol to antioxidant activity in different extracts of Myrmecodia platytyrea. S Afr J Bot 115:94-99

13. Jason RJ, Mohamed IM, Selva GR, Sankar M (2014) Quantification of colchicine in various parts of Gloriosa superba by HPLC. J Chem Pharm Sci 2:53-55

14. Finnie JF, Van Staden J (1991) Isolation of colchicine from Sandersonia aurantiaca and Gloriosa superba variation in the alkaloid levels of plants grown in vivo. J Plant Physiol 138:691-695. https://doi.org/10.1016/ S0176-1617(11)81317-9

15. Sarin R, Rishi A, Kumar A (2010) In vivo and In vitro estimation of colchicine in Gloriosa superba L. by high pressure liquid chromatography. J Exp Sci 1:1-2

16. Basak UC, Dash D, Mahapatra AK (2012) Estimation of colchicine in tubers of Gloriosa superba L. originated from different agroclimatic zones of Odisha, India. Int J Pharmacogn Phytochem Res 4:157-161

17. Kavina J, Gopi R, Panneerselvam R (2011) Quantification of colchicine in seed and tuber samples of Gloriosa superba by high performance liquid chromatography method crop growth as evidenced by increased seedling emergence. J Appl Pharm Sci 1:116-119

18. Murashige T, Skoog F (1962) A revised medium for rapid growth and bio assays with tobacco tissue cultures. Physiol Plant 15:473-497

19. Rathod D, Patel I (2016) Comparative preliminary phytochemical studies of in vivo and in vitro extracts of Gloriosa superba L. Int J Pharm Bio Sci 7:20-23

20. Das K, Tiwari RKS, Shrivastava DK (2010) Techniques for evaluation of medicinal plant products as antimicrobial agent: current methods and future trends. J Med Plants Res 4:104-111. https://doi.org/10.5897/ JMPR09.030

21. ICH Harmonized Tripartite Guideline (2005) Validation of analytical procedures: text and methodology Q2(R1). In: International conference on harmonization, Geneva, Switzerland

22. Alam P, Ali M, Singh R, Shakeel F (2011) A new HPTLC densitometric method for analysis of swertiamarin in Enicostemma littorale and commercial formulations. Nat Prod Res 25:17-25. https://doi.org/10.1080/ 14786411003754348

23. Debnath M, Pandey M, Chikara SK (2011) Physiological and molecular characterization of in vitro cultures of an endemic medicinal herb, Chlorophytum borivilianum, under abiotic stress. Afr J Biotechnol 10:7356-7366. https://doi.org/10.5897/AJB11.445

24. Gantait S, Mandal N, Das PK (2011) In vitro accelerated mass propagation and ex vitro evaluation of Aloe vera $\mathrm{L}$. with aloin content and superoxide dismutase activity. Nat Prod Res 25:1370-1378. https://doi.org/10.1080/ 14786419.2010 .541885

25. Panigrahi J, Gantait S, Patel IC (2017) An efficient in vitro approach for direct regeneration and callogenesis of Adhatoda vasica Nees, a potential source of quinazoline alkaloids. Natl Acad Sci Lett. https://doi.org/10. 1007/s40009-017-0596-8 
26. Ghosh S, Ghosh B, Jha S (2007) In vitro tuberisation of Gloriosa superba L. on basal medium. Sci Hortic 114:220-223. https://doi.org/10.1016/j.scien ta.2007.06.008

27. Kolar AB, Basha MG (2014) In vitro tuberization and quantitative analysis of colchicine using hptlc in Gloriosa superba L. an endangered medicinal plant of Pachamalai hills, a part of Eastern Ghats, Tamil Nadu. Int J Pharma Bio Sci 5:300-310

28. Kumar CN, Jadhav SK, Tiwari KL, Afaque Q (2015) In vitro tuberization and colchicine content analysis of Gloriosa superba L. Biotechnology 14:142-147. https://doi.org/10.3923/biotech.2015.142.147

29. Pandey D, Parida S, Dey A (2016) Comparative HPTLC analysis of bioactive marker barbaloin from in vitro and naturally grown Aloe vera. Rev Bras 26:161-167. https://doi.org/10.1016/j.bjp.2015.08.016

30. Pandey DK, Dey SA (2015) Comparative HPTLC analysis of antioxidant compound gallic acid from in vitro and naturally grown Stevia rebaudiana. J Biol Act Prod Nat 5(6):397-405. https://doi.org/10.1080/22311866. 2014.902753

31. Ekiert RJ, Szopa A, Ekiert H, Krzek J, Dzik E (2013) Analysis of lignans in Schisandra chinensis fruits, leaves, biomasses from in vitro cultures and food supplements. J Funct Foods 5:1576-1581. https://doi.org/10.1016/j. jff.2013.06.008

32. Panigrahi J, Patel IC (2016) Quantification of stigmasterol under in vivo and in vitro plant extracts of Chlorophytum sps. Int J Pharm Bio Sci 7:278-283

33. Panigrahi J, Gantait S, Patel IC (2017) Concurrent production and relative quantification of vasicinone from in vivo and in vitro plant parts of Malabar nut (Adhatoda vasica Nees). 3 Biotech 7(5):1-8. https://doi.org/ 10.1007/s13205-017-0882-7

34. Duncan D (1955) Multiple range and multiple F tests. Biometrics 11(1):1-42. https://doi.org/10.2307/3001478

\section{Publisher's Note}

Springer Nature remains neutral with regard to jurisdictional claims in published maps and institutional affiliations.

\section{Submit your manuscript to a SpringerOpen ${ }^{\circ}$ journal and benefit from:}

- Convenient online submission

- Rigorous peer review

- Open access: articles freely available online

- High visibility within the field

- Retaining the copyright to your article

Submit your next manuscript at $\boldsymbol{\nabla}$ springeropen.com 